\title{
Lymph node metastasis risk according to the depth of invasion in early gastric cancers confined to the mucosal layer
}

\author{
Young-Il Kim ${ }^{1} \cdot$ Jun Ho Lee ${ }^{1,2} \cdot$ Myeong-Cherl $\operatorname{Kook}^{1} \cdot$ Jong Yeul Lee $^{1} \cdot$ \\ Chan Gyoo Kim ${ }^{1} \cdot$ Keun Won Ryu ${ }^{1}$ 'Young-Woo Kim ${ }^{1} \cdot$ Il Ju Choi ${ }^{1}$
}

Received: 1 May 2015/Accepted: 7 August 2015/Published online: 25 August 2015

(C) The International Gastric Cancer Association and The Japanese Gastric Cancer Association 2015

\begin{abstract}
Background Early gastric cancers (EGCs) within the mucosal layer of the gastric wall have a small risk of lymph node $(\mathrm{LN})$ metastasis.

Methods We reviewed clinicopathology data for patients who underwent surgery for EGC between 2001 and 2013 at the National Cancer Center, Korea. Poisson regression analyses were performed to compare the risk of $\mathrm{LN}$ metastasis according to the depth of tumor invasion in patients with mucosal EGCs.

Results Among the 1776 EGC patients included, 580 $(32.7 \%)$ had tumors confined to the lamina propria (LP; LP group) and $1196(67.3 \%)$ had tumors invading the muscularis mucosae (MM; MM group). Seventy-one patients $(4.0 \%)$ had LN metastasis, and the MM group had a significantly higher rate of $\mathrm{LN}$ metastasis (59 patients, $4.9 \%$ ) than the LP group (12 patients, $2.1 \% ; P=0.004$ ). A multivariate analysis showed that tumors invading the MM (adjusted risk ratio 1.95; $P=0.045$ ) were significantly associated with LN metastasis in addition to wellknown risk factors, including tumor size greater than $3 \mathrm{~cm}$, presence of ulceration, undifferentiated histologic type, and lymphovascular invasion. The incidence of $\mathrm{LN}$ metastasis was $1.87 \%$ (95\% confidence interval $0.23-6.59 \%$ ) within tumors invading the MM that met the expanded criterion
\end{abstract}

Y.-I. Kim and J. H. Lee contributed equally to this work.

Il Ju Choi

cij1224@ncc.re.kr

1 Center for Gastric Cancer, National Cancer Center, 323 Ilsanro Ilsandong-gu, Goyang, Gyeonggi 410-769, Korea

2 Present Address: Department of Surgery, Sungkyunkwan University School of Medicine, Samsung Medical Center, Seoul, Korea for endoscopic resection of differentiated histologic type of size $3 \mathrm{~cm}$ or smaller with ulceration. LN metastasis was not found in tumors meeting the absolute criteria for endoscopic resection.

Conclusions EGCs invading the MM had a higher rate of lymph node metastasis than those confined to the LP. Further study is needed to evaluate whether different curative treatment criteria are needed for LP-confined and MM-invading EGCs.

Keywords Early gastric cancer - Muscularis mucosae · Lamina propria $\cdot$ Lymph node metastasis $\cdot$ Risk

\section{Introduction}

Endoscopic resection is an important treatment modality for early cancers of the upper gastrointestinal tract when there is no risk of lymph node metastasis [1]. However, the endoscopic resection indication criteria are different for esophageal and gastric cancers depending on the depth of tumor invasion, especially for tumors confined to the mucosal layer. In esophageal squamous cell carcinoma, endoscopic resection is indicated only for tumors confined to the lamina propria (LP) $[1,2]$, because tumors invading the muscularis mucosae (MM) have significant risk of lymph node metastasis, with an incidence of 11.8-12.5\% $[3,4]$. However, in mucosal gastric cancer, the endoscopic resection indication criteria do not take into consideration whether tumors are confined to the LP or invade the MM [1].

Lymphovascular invasion is a primary risk factor associated with lymph node metastasis in early gastric cancer (EGC) [5, 6]. In the gastric mucosa, lymphatic capillaries are found only in the deeper third of the LP, which is 
adjacent to the MM [7, 8], and these structures are less abundant in the gastric mucosa as compared with the esophageal mucosal layer [9]. Current endoscopic resection indication criteria for EGC are based on analyses of many surgically resected specimens, but do not consider the depth of tumor invasion within the mucosal layer [5]. In a study of Western patients, Hölscher et al. [10] reported different rates of lymph node metastasis in mucosal EGCs according to the depth of invasion; the rate of lymph node metastasis was $12.8 \%$ in patients with tumors invading the $\mathrm{MM}$, but $0 \%$ in patients whose tumors were confined to the LP. Thus, endoscopic resection is a questionable modality for EGC lesions invading the MM. Nevertheless, controversy remains, because most of the large-scale Eastern studies have not considered the depth of tumor invasion within the mucosal layer.

Because of these disparities, we investigated the differences in lymph node metastasis rates and risk factors in patients with mucosal EGCs according to the invasion depth.

\section{Patients and methods}

\section{Study population}

From January 2001 to December 2013, 3885 patients underwent gastrectomy for EGCs at the National Cancer Center, Korea. Following a retrospective review of the clinical and pathology data for these patients, only patients with a diagnosis of mucosal EGC were considered for inclusion in the present study. The exclusion criteria for the study were as follows: (1) patients without information on the exact depth of invasion, (2) patients who had both tumors confined to the LP and tumors invading the MM at the same time, and (3) patients who had already undergone a gastrectomy. Then, all included patients were classified into the LP group or MM group according to the depth of invasion. This study was approved by the Institutional Review Board of the National Cancer Center, Korea (Institutional Review Board number NCC2014-0214).

The clinical data analyzed included baseline demographics and endoscopic findings. The pathology data analyzed included tumor location, size, histologic type, ulceration, presence of lymphovascular invasion, and lymph node metastasis.

\section{Surgical procedures}

Laparoscopic or open radical gastrectomy with lymph node dissection was performed for all included patients. Billroth I or Billroth II reconstruction was performed for patients who underwent a partial gastrectomy, and Roux-en-Y esophagojejunostomy was performed for those patients who underwent total gastrectomy. All patients underwent $\mathrm{D} 1+$ or greater lymph node dissection based on the guidelines of the Japanese Gastric Cancer Association [11].

Twenty-three patients who underwent gastrectomy after endoscopic resection because of noncurative resection or undifferentiated tumor histologic type on the final pathology report were also included. Most patients underwent endoscopic submucosal dissection, except for two patients who underwent endoscopic mucosal resection. Detailed endoscopic resection procedures were described in a previous study [12].

\section{Pathological evaluation}

All resected specimens were fixed in $10 \%$ formalin for pathological evaluation. The fixed specimens were sliced serially at 4-mm intervals, embedded in paraffin blocks, and stained with hematoxylin and eosin. All resected lymph nodes were also prepared for pathological evaluation. All the pathological evaluations were performed by a single specialized pathologist for gastric cancer (M.-C. KooK). Tumor histologic types were classified according to the Japanese classification of gastric cancer [13] and the World Health Organization classification of gastric cancer [14]. The differentiated histologic type included papillary adenocarcinoma and well and moderately differentiated tubular adenocarcinoma, whereas the undifferentiated histologic type included poorly differentiated adenocarcinoma, signet ring cell carcinoma, and mucinous adenocarcinoma [11]. Tumors having both differentiated and undifferentiated histologic components were classified according to the histologic type constituting most of the tumor (50\% or more) $[11,14]$. The presence of ulceration was based on the pathological or endoscopic evidence of ulcer findings. In patients with multiple tumors, one main lesion was selected and included in the analyses according to the following order of priority: (1) tumors with lymphovascular invasion, (2) tumors of undifferentiated histologic type, and (3) tumors of the largest size.

\section{Statistical analysis}

Baseline demographics and pathological characteristics were compared according to the depth of tumor invasion. Chi-square and Fisher's exact tests were used for comparisons of categorical variables, whereas the Student's $t$ test or the Mann-Whitney test were used for comparisons of continuous variables. To analyze the risk factors associated with lymph node metastasis in mucosal EGCs, Poisson regression analyses were performed in all included patients as well as in subgroups of patients according to the depth of invasion. Variables that showed a difference with a $P$ value less than 0.10 between patients with lymph node 
metastasis and those without lymph node metastasis were included in covariate for multivariate analyses. The incidences of lymph node metastasis were estimated with a $95 \%$ confidence interval (CI) based on the exact binomial distribution. All statistical analyses were performed with STATA 12.1 (STATA, College Station, TX, USA). $P$ values less than 0.05 were considered statistically significant.

\section{Results}

\section{Baseline clinical and pathological characteristics}

Of the 3885 EGC patients who underwent surgery, 1992 had mucosal EGC. Of these, 1776 patients were included in the final analyses (Fig. 1). The median age of the patients was 56 years (interquartile range $47-66$ years), and $61.0 \%$ of the patients were male.

Of the included patients, 580 patients $(32.7 \%)$ were classified into the LP group and 1196 (67.3\%) were classified into the MM group. Patients in the MM group were significantly older and included more male patients. Tumors in MM group were larger, included more tumors of differentiated histologic type, and presented with a larger proportion of ulcer findings and lymphovascular invasion with statistical significance (Table 1).

\section{Risk factors associated with lymph node metastasis}

Of the 1776 patients with mucosal EGCs, 71 patients (4.0\%) had lymph node metastasis, with 12 patients $(2.1 \%)$ in the LP group and 59 (4.9\%) in the MM group $(P=0.004)$. The rate of lymph node metastasis was significantly higher in the MM group than in the LP group (Table 1).

In the univariate analyses, younger age, tumor size greater than $3 \mathrm{~cm}$, undifferentiated histologic type, ulcer findings, lymphovascular invasion, and tumors invading the MM were the factors significantly associated with lymph node metastasis. The multivariate analysis found that tumor invasion into the MM was an independent risk factor for lymph node metastasis (adjusted risk ratio 1.95; $95 \%$ CI 1.02-3.73; $P=0.045$ ). In comparison with tumor size of $2.0 \mathrm{~cm}$ or less, tumor size greater than $3 \mathrm{~cm}$ was a significant risk factor for lymph node metastasis (adjusted risk ratio $3.10 ; 95 \%$ CI $1.54-6.27 ; P=0.002$ ). In addition, undifferentiated histologic type, ulcer findings, and lymphovascular invasion were also independent risk factors for lymph node metastasis (Table 2).

Risk factors were analyzed according to the depth of tumor invasion. A multivariate analysis showed that tumor size greater than $3 \mathrm{~cm}$ and lymphovascular invasion were independent risk factors associated with lymph node metastasis in patients with tumors confined to the LP (Table 3). In patients with tumors invading the MM, risk factors for lymph node metastasis were tumor size greater than $3 \mathrm{~cm}$, undifferentiated histologic type, ulcer findings, and lymphovascular invasion (Table 4).

\section{Incidence of lymph node metastasis in patients with EGCs meeting the endoscopic resection indication criteria}

Of 1776 patients with mucosal EGCs, 961 had lesions meeting the absolute indication criteria (234 lesions) or
Fig. 1 Flowchart of the study design. $E G C$ early gastric cancer

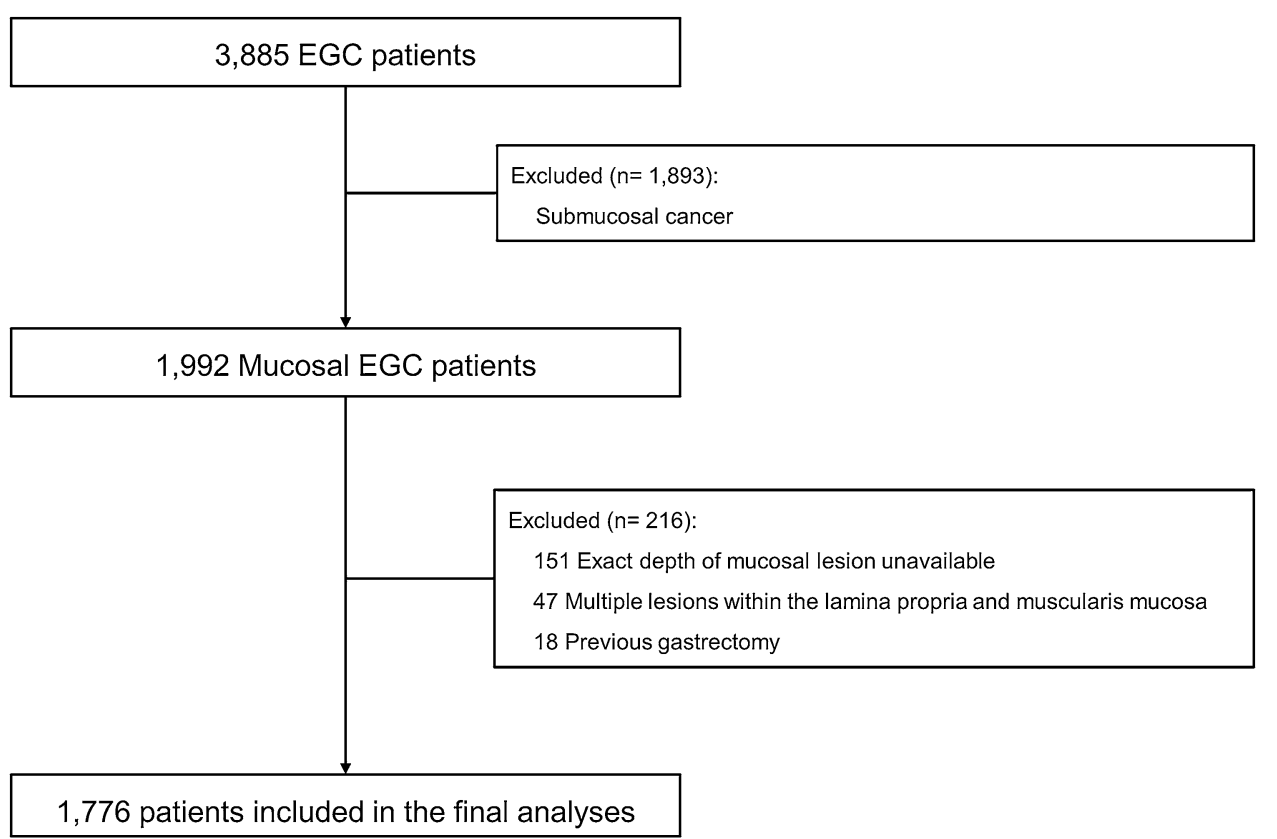


Table 1 Baseline demographics and tumor characteristics

\begin{tabular}{|c|c|c|c|}
\hline & \multicolumn{2}{|l|}{ Tumor depth } & \multirow[t]{2}{*}{$P$} \\
\hline & $\mathrm{LP}(n=580)$ & $\mathrm{MM}(n=1196)$ & \\
\hline Age (years) & & & $<0.001$ \\
\hline Median & 53 & 57 & \\
\hline IQR & $45-64$ & $48-66$ & \\
\hline Sex & & & 0.007 \\
\hline Female & $252(43.5 \%)$ & $440(36.8 \%)$ & \\
\hline Male & $328(56.5 \%)$ & $756(63.2 \%)$ & \\
\hline Comorbid disease & $194(33.5 \%)$ & $453(37.9 \%)$ & 0.069 \\
\hline Hypertension & $134(23.1 \%)$ & $312(26.1 \%)$ & \\
\hline Diabetes mellitus & $57(9.8 \%)$ & $148(12.4 \%)$ & \\
\hline Cardiovascular disease & $17(2.9 \%)$ & $31(2.6 \%)$ & \\
\hline Chronic liver disease & $21(3.6 \%)$ & $66(5.5 \%)$ & \\
\hline Chronic pulmonary disease & $4(0.7 \%)$ & $21(1.8 \%)$ & \\
\hline Tumor location & & & $<0.001$ \\
\hline Upper third & $47(8.1 \%)$ & $90(7.5 \%)$ & \\
\hline Middle third & $264(45.5 \%)$ & $452(37.8 \%)$ & \\
\hline Lower third & $254(43.8 \%)$ & $571(47.7 \%)$ & \\
\hline More than half of the stomach & $15(2.6 \%)$ & $83(6.9 \%)$ & \\
\hline Mean tumor size \pm SD $(\mathrm{cm})$ & $2.4 \pm 1.5$ & $3.3 \pm 1.9$ & $<0.001$ \\
\hline Tumor histologic type & & & $<0.001$ \\
\hline Differentiated & $210(36.2 \%)$ & $616(51.5 \%)$ & \\
\hline Undifferentiated & $370(63.8 \%)$ & $580(48.5 \%)$ & \\
\hline Presence of ulceration & $147(25.3)$ & $401(33.5 \%)$ & $<0.001$ \\
\hline Presence of multiple tumors & $26(4.5 \%)$ & $33(2.8 \%)$ & 0.057 \\
\hline Presence of lymphovascular invasion & $4(0.7 \%)$ & $37(3.1 \%)$ & 0.002 \\
\hline Lymph node metastasis & $12(2.1 \%)$ & $59(4.9 \%)$ & 0.004 \\
\hline
\end{tabular}

$I Q R$ interquartile range, $L P$ lamina propria, $M M$ muscularis mucosae, $S D$ standard deviation expanded indication criteria (727 lesions) for endoscopic resection, and lymph node metastasis was found in six patients $(0.62 \%$; $95 \%$ CI $0.23-1.35 \%)$. Lymph node metastasis was found in two patients with tumors confined to the LP $(0.59 \% ; 95 \%$ CI $0.07-2.11 \%)$ and in four patients with tumors invading the MM, but this was not statistically significant $(0.64 \%$; $95 \%$ CI $0.18-1.64 \%$; $P=0.920$ ). For tumors meeting the absolute indication criteria for endoscopic resection, there were no lymph node metastases. All lymph node metastases were found in mucosal EGCs that met the expanded indication criteria for endoscopic resection. In patients with tumors confined to the LP, lymph node metastases were found only in tumors included in the expanded indication criterion of undifferentiated histologic type of size $2 \mathrm{~cm}$ or smaller without ulceration. In contrast, in patients with tumors invading the MM, lymph node metastases were found in tumors that met all the expanded indication criteria. In particular, the incidence of lymph node metastasis was $1.87 \%$ (2 of 107 patients; $95 \%$ CI $0.23-6.59 \%$ ) in differentiated histologic type tumors $3 \mathrm{~cm}$ or smaller with ulceration (Table 5).

\section{Discussion}

We investigated the risk of lymph node metastasis in mucosal EGC patients according to the depth of tumor invasion. The rate of lymph node metastasis was significantly higher in patients with tumors invading the MM than in those with tumors confined to the LP. Furthermore, tumor invasion into the MM was found to be an independent risk factor for lymph node metastasis in the multivariate analysis.

In the treatment of early gastrointestinal cancers, endoscopic resection is performed for lesions that are not likely to metastasize to the lymph nodes. In general, endoscopic resection is indicated for tumors confined to the LP in early esophageal cancers [1, 2]. For early colorectal cancers, endoscopic resection is performed for tumors that invade down to the shallow submucosal layer (submucosal invasion less than $1000 \mu \mathrm{m}$ ) [15]. The indication criteria for endoscopic resection based on the depth of tumor invasion may be different for cancers arising in different portions of the gastrointestinal tract because of the distribution of the 
Table 2 Factors associated with lymph node metastasis in all patients

\begin{tabular}{|c|c|c|c|c|c|c|c|}
\hline & \multirow[t]{2}{*}{ No. } & \multicolumn{3}{|c|}{ Univariate analysis } & \multicolumn{3}{|c|}{ Multivariate analysis } \\
\hline & & $\mathrm{cRR}^{\mathrm{a}}$ & $95 \% \mathrm{CI}$ & $P$ & $\mathrm{aRR}^{\mathrm{a}}$ & $95 \% \mathrm{CI}$ & $P$ \\
\hline Age & 1776 & 0.97 & $0.95-0.99$ & 0.004 & 0.98 & $0.96-1.00$ & 0.055 \\
\hline \multicolumn{8}{|l|}{ Sex } \\
\hline Female & 692 & 1.00 & & & & & \\
\hline Male & 1084 & 0.78 & $0.49-1.24$ & 0.293 & & & \\
\hline \multicolumn{8}{|l|}{ Comorbidity } \\
\hline Absence & 1129 & 1.00 & & & & & \\
\hline Presence & 647 & 0.84 & $0.51-1.37$ & 0.480 & & & \\
\hline \multicolumn{8}{|l|}{ Tumor location } \\
\hline Lower third & 825 & 1.00 & & & & & \\
\hline Middle third & 716 & 0.77 & $0.46-1.29$ & 0.317 & & & \\
\hline Upper third & 137 & 0.33 & $0.08-1.39$ & 0.132 & & & \\
\hline \multicolumn{8}{|l|}{ Tumor size } \\
\hline$\leq 2.0 \mathrm{~cm}$ & 663 & 1.00 & & & 1.00 & & \\
\hline $2.1-3.0 \mathrm{~cm}$ & 413 & 2.25 & $0.99-5.06$ & 0.050 & 1.68 & $0.74-3.82$ & 0.213 \\
\hline$>3.0 \mathrm{~cm}$ & 700 & 4.45 & $2.25-8.81$ & $<0.001$ & 3.10 & $1.54-6.27$ & 0.002 \\
\hline \multicolumn{8}{|l|}{ Tumor histologic type } \\
\hline Differentiated & 826 & 1.00 & & & 1.00 & & \\
\hline Undifferentiated & 950 & 3.25 & $1.84-5.74$ & $<0.001$ & 2.96 & $1.63-5.37$ & $<0.001$ \\
\hline \multicolumn{8}{|l|}{ Ulceration } \\
\hline Absence & 1228 & 1.00 & & & 1.00 & & \\
\hline Presence & 548 & 2.73 & $1.71-4.34$ & $<0.001$ & 2.25 & $1.40-3.61$ & 0.001 \\
\hline \multicolumn{8}{|l|}{ Multiple tumors } \\
\hline No & 1717 & 1.00 & & & & & \\
\hline Yes & 59 & 0.42 & $0.06-2.99$ & 0.383 & & & \\
\hline \multicolumn{8}{|c|}{ Lymphovascular invasion } \\
\hline Absence & 1735 & 1.00 & & & 1.00 & & \\
\hline Presence & 41 & 6.94 & $3.55-13.54$ & $<0.001$ & 8.12 & $4.07-16.22$ & $<0.001$ \\
\hline \multicolumn{8}{|l|}{ Depth of tumor invasion } \\
\hline Lamina propria & 582 & 1.00 & & & 1.00 & & \\
\hline Muscularis mucosae & 1196 & 2.38 & $1.28-4.44$ & 0.006 & 1.95 & $1.02-3.73$ & 0.045 \\
\hline
\end{tabular}

$a R R$ adjusted risk ratio, $C I$ confidence interval, $c R R$ crude risk ratio

${ }^{\mathrm{a}}$ The risk ratio was obtained from Poisson regression analysis. lymphatic vessels; the esophageal mucosal layer has abundant lymphatic vessels, whereas there are hardly any lymphatic vessels in the colonic mucosal layer [16], and significantly fewer than in the submucosal layer [17]. In the stomach, lymphatic vessels originate in the deep LP adjacent to the MM [7, 8]. The diameter of lymphatic vessels tends to be larger as they enter the deep LP to the submucosal layer [18]. Thus, lymph node metastasis risk in gastric cancer might be different for cancers invading the LP or the MM because lymphovascular invasion is the most important risk factor in gastric cancer. Until now, however, the risk of lymph node metastasis for EGC based on the depth of tumor invasion into the mucosal layer has not been well studied.

In a study of Western patients, Hölscher et al. [10] reported the risk of lymph node metastasis among tumors confined to the LP and those invading the MM. The rates of lymph node metastasis were $0 \%$ in tumors confined to the epithelium and LP, $12.8 \%$ in those invading the MM, and $16-40 \%$ in those invading the submucosa. However, this study only evaluated the risk of lymph node metastasis in 47 patients with mucosal EGC. Additionally, previous Japanese or Korean studies that evaluated lymph node incidence of mucosal EGCs did not differentiate between the LP and the MM [5, 19, 20]. In the present study, we included a large number of EGC patients, and found that the risk and incidence of lymph node metastasis was significantly higher in MM-invading cancer than in LP-confined cancer ( $4.9 \%$ vs $2.1 \%$, respectively; $P=0.004$ ).

We also identified significant risk factors for lymph node metastasis in mucosal EGCs as tumor size larger than $3 \mathrm{~cm}$, undifferentiated histologic type, the presence of 
Table 3 Factors associated with lymph node metastasis in patients with tumors confined to the lamina propria

\begin{tabular}{|c|c|c|c|c|c|c|c|}
\hline & \multirow[t]{2}{*}{ No } & \multicolumn{3}{|c|}{ Univariate analysis } & \multicolumn{3}{|c|}{ Multivariate analysis } \\
\hline & & $\mathrm{cRR}^{\mathrm{a}}$ & $95 \% \mathrm{CI}$ & $P$ & $\mathrm{aRR}^{\mathrm{a}}$ & $95 \% \mathrm{CI}$ & $P$ \\
\hline Age & 580 & 0.95 & $0.91-1.00$ & 0.059 & 0.98 & $0.92-1.03$ & 0.389 \\
\hline \multicolumn{8}{|l|}{ Sex } \\
\hline Female & 252 & 1.00 & & & & & \\
\hline Male & 328 & 0.77 & $0.25-2.38$ & 0.648 & & & \\
\hline \multicolumn{8}{|l|}{ Comorbidity } \\
\hline Absence & 386 & 1.00 & & & & & \\
\hline Presence & 194 & 0.40 & $0.09-1.82$ & 0.234 & & & \\
\hline \multicolumn{8}{|l|}{ Tumor location } \\
\hline Lower third & 254 & 1.00 & & & & & \\
\hline Middle third & 264 & 0.80 & $0.24-2.63$ & 0.715 & & & \\
\hline Upper third & 47 & NA & NA & NA & & & \\
\hline \multicolumn{8}{|l|}{ Tumor size } \\
\hline$\leq 2.0 \mathrm{~cm}$ & 301 & 1.00 & & & 1.00 & & \\
\hline $2.1-3.0 \mathrm{~cm}$ & 125 & 1.20 & $0.22-6.57$ & 0.830 & 0.56 & $0.09-3.67$ & 0.549 \\
\hline$>3.0 \mathrm{~cm}$ & 154 & 2.93 & $0.83-10.39$ & 0.096 & 4.20 & $1.11-15.80$ & 0.034 \\
\hline \multicolumn{8}{|c|}{ Tumor histologic type } \\
\hline Differentiated & 210 & 1.00 & & & 1.00 & & \\
\hline Undifferentiated & 370 & 6.24 & $0.81-48.36$ & 0.080 & 5.58 & $0.65-47.86$ & 0.117 \\
\hline \multicolumn{8}{|l|}{ Ulceration } \\
\hline Absence & 433 & 1.00 & & & & & \\
\hline Presence & 147 & 2.10 & $0.67-6.63$ & 0.204 & & & \\
\hline \multicolumn{8}{|l|}{ Multiple tumors } \\
\hline No & 554 & 1.00 & & & & & \\
\hline Yes & 26 & NA & NA & NA & & & \\
\hline \multicolumn{8}{|c|}{ Lymphovascular invasion } \\
\hline Absence & 576 & 1.00 & & & 1.00 & & \\
\hline Presence & 4 & 28.80 & $6.31-131.44$ & $<0.001$ & 50.64 & $8.07-317.86$ & $<0.001$ \\
\hline
\end{tabular}

ulceration, and lymphovascular invasion. A systematic review of 45 studies reported that age younger than 57 years, tumor location in the middle part, larger tumor size, depressed tumor type, ulcer findings, undifferentiated histologic type, and lymphatic tumor invasion were significantly associated with lymph node metastasis in mucosal cancer [6], which were findings similar to those in our study. However, previous studies did not consider the depth of invasion within the mucosal layer as a risk factor for lymph node metastasis, which we found to be an important risk factor for lymph node metastasis in mucosal cancer.

The risk factors for lymph node metastasis were different for tumors confined to the LP compared with those invading the MM. Tumor size greater than $3 \mathrm{~cm}$ and lymphovascular invasion were risk factors for lymph node metastasis in patients with either LP-confined or MM-invading tumors, whereas undifferentiated histologic type and ulcer findings were only risk factors for patients with tumors invading the MM. In our study, half as many patients had tumors confined to the LP as those with tumors invading the MM. Although the risk factors associated with lymph node metastasis seem to vary depending on the depth of tumor invasion in the multivariate analysis, the univariate analysis showed that patients with tumors confined to the LP had odds ratios for risk factors similar to those with tumors invading the MM. Thus, the differences in risk factors identified between LP-confined and MMinvading tumors might be due to the small sample size and the overall lower lymph node metastasis rates in LP-confined cancer.

Gotoda et al. [5] reported that patients with mucosal EGC of the differentiated histologic type that met the indication criteria for endoscopic resection had a negligible risk of lymph node metastasis. In the present study, the incidence of lymph node metastasis was $0 \%$ in the 
Table 4 Factors associated with lymph node metastasis in patients with tumors invading the muscularis mucosae

\begin{tabular}{|c|c|c|c|c|c|c|c|}
\hline & \multirow[t]{2}{*}{ No } & \multicolumn{3}{|c|}{ Univariate analysis } & \multicolumn{3}{|c|}{ Multivariate analysis } \\
\hline & & $\mathrm{cRR}^{\mathrm{a}}$ & $95 \% \mathrm{CI}$ & $P$ & $\mathrm{aRR}^{\mathrm{a}}$ & $95 \% \mathrm{CI}$ & $P$ \\
\hline Age & 1196 & 0.97 & $0.95-0.99$ & 0.007 & 0.98 & $0.96-1.01$ & 0.126 \\
\hline \multicolumn{8}{|l|}{ Sex } \\
\hline Female & 440 & 1.00 & & & & & \\
\hline Male & 756 & 0.74 & $0.44-1.24$ & 0.248 & & & \\
\hline \multicolumn{8}{|l|}{ Comorbidity } \\
\hline Absence & 743 & 1.00 & & & & & \\
\hline Presence & 453 & 0.91 & $0.53-1.54$ & 0.718 & & & \\
\hline \multicolumn{8}{|l|}{ Tumor location } \\
\hline Lower third & 571 & 1.00 & & & & & \\
\hline Middle third & 452 & 0.80 & $0.45-1.42$ & 0.447 & & & \\
\hline Upper third & 90 & 0.42 & $0.10-1.77$ & 0.239 & & & \\
\hline \multicolumn{8}{|l|}{ Tumor size } \\
\hline$\leq 2.0 \mathrm{~cm}$ & 362 & 1.00 & & & 1.00 & & \\
\hline $2.1-3.0 \mathrm{~cm}$ & 288 & 2.51 & $0.94-6.70$ & 0.065 & 2.06 & $0.77-5.52$ & 0.150 \\
\hline$>3 \mathrm{~cm}$ & 546 & 4.53 & $1.92-10.67$ & 0.001 & 3.38 & $1.42-8.01$ & 0.006 \\
\hline \multicolumn{8}{|c|}{ Tumor histologic type } \\
\hline Differentiated & 616 & 1.00 & & & 1.00 & & \\
\hline Undifferentiated & 580 & 3.41 & $1.87-6.22$ & $<0.001$ & 2.80 & $1.50-5.22$ & 0.001 \\
\hline \multicolumn{8}{|l|}{ Ulceration } \\
\hline Absence & 795 & 1.00 & & & 1.00 & & \\
\hline Presence & 401 & 2.70 & $1.61-4.52$ & $<0.001$ & 2.38 & $1.41-4.02$ & 0.001 \\
\hline \multicolumn{8}{|l|}{ Multiple tumors } \\
\hline No & 1163 & 1.00 & & & & & \\
\hline Yes & 33 & 0.61 & $0.08-4.39$ & 0.621 & & & \\
\hline \multicolumn{8}{|c|}{ Lymphovascular invasion } \\
\hline Absence & 1159 & 1.00 & & & 1.00 & & \\
\hline Presence & 37 & 4.91 & $2.33-10.35$ & $<0.001$ & 6.57 & $3.04-14.17$ & $<0.001$ \\
\hline
\end{tabular}

$a R R$ adjusted risk ratio, $C I$ confidence interval, $c R R$ crude risk ratio

a The risk ratio was obtained from Poisson regression analysis. mucosal EGCs that met the absolute indication criteria for endoscopic resection. However, lymph node metastases were observed in the mucosal EGCs that met the expanded indication criteria for endoscopic resection. In the EGC lesions invading the MM, lymph node metastases were detected in patients meeting all the expanded indication criteria for endoscopic resection, especially in those meeting the criterion of differentiated intramucosal cancer of size $3 \mathrm{~cm}$ or smaller with ulceration. In general, endoscopic resection is performed for EGC lesions meeting the expanded indication criteria, because those lesions have zero risk of lymph node metastasis, with an upper limit of the $95 \%$ CI of less than $1 \%$ [5]. However, in the present study, the MM-invading differentiated lesions of size $3 \mathrm{~cm}$ or smaller with ulceration had a high incidence of lymph node metastasis $(1.87 \%)$. In the EGC lesions confined to the LP, lymph node metastasis was not observed in differentiated tumors meeting the expanded indication criteria. Thus, differentiated EGC lesions invading the MM that meet the expanded indication criteria for endoscopic resection might have some risk of lymph node metastasis, especially for those with tumors with ulceration. Further studies are needed on these EGCs to evaluate the association between the risk of lymph node metastasis and other factors, such as the presence of mixed histologic types [21, 22].

Additionally, Hirasawa et al. [23] also reported that undifferentiated mucosal EGCs which met the expanded indication criteria had zero risk of lymph node metastasis. Several other studies have also reported favorable outcomes after endoscopic submucosal dissection for undifferentiated mucosal EGCs [24-26]. However, in the present study, lymph node metastases were observed in patients with mucosal EGCs confined to the LP as well as in patients with tumors invading the MM. Thus, the risk of lymph node metastasis should not be ignored for 
Table 5 Incidence of lymph node metastasis in early gastric cancer within the criteria for endoscopic resection

\begin{tabular}{|c|c|c|c|c|c|c|}
\hline & \multicolumn{2}{|l|}{ All tumors } & \multicolumn{2}{|c|}{ Lamina propria invasion } & \multicolumn{2}{|c|}{$\begin{array}{l}\text { Muscularis mucosae } \\
\text { invasion }\end{array}$} \\
\hline & Incidence & $95 \% \mathrm{CI}^{\mathrm{a}}$ & Incidence & $95 \% \mathrm{CI}^{\mathrm{a}}$ & Incidence & $95 \% \mathrm{CI}^{\mathrm{a}}$ \\
\hline All & $\begin{array}{l}0.62 \%(6 / \\
961)\end{array}$ & $0.23-1.35 \%$ & $\begin{array}{l}0.59 \%(2 / \\
339)\end{array}$ & $0.07-2.11 \%$ & $\begin{array}{l}0.64 \%(4 / \\
622)\end{array}$ & $0.18-1.64 \%$ \\
\hline \multicolumn{7}{|l|}{ Absolute indication criteria } \\
\hline $\begin{array}{l}\text { Differentiated histologic type, LVI negative, ulcer } \\
\text { negative, size } \leq 2 \mathrm{~cm}\end{array}$ & $\begin{array}{c}0 \%(0 / \\
234)\end{array}$ & $0-1.56 \%{ }^{\mathrm{b}}$ & $0 \%(0 / 91)$ & $0-3.97 \%{ }^{\mathrm{b}}$ & $\begin{array}{c}0 \%(0 / \\
143)\end{array}$ & $0-2.55 \%^{\mathrm{b}}$ \\
\hline \multicolumn{7}{|l|}{ Expanded indication criteria } \\
\hline $\begin{array}{l}\text { Differentiated histologic type, LVI negative, ulcer } \\
\text { negative, size }>2 \mathrm{~cm}\end{array}$ & $\begin{array}{l}0.29 \%(1 / \\
341)\end{array}$ & $0.01-1.62 \%$ & $0 \%(0 / 79)$ & $0-4.56 \%^{\mathrm{b}}$ & $\begin{array}{l}0.38 \%(1 / \\
262)\end{array}$ & $0.01-2.11 \%$ \\
\hline $\begin{array}{l}\text { Differentiated histologic type, LVI negative, ulcer } \\
\text { positive, size } \leq 3 \mathrm{~cm}\end{array}$ & $\begin{array}{l}1.55 \%(2 / \\
129)\end{array}$ & $0.19-5.49 \%$ & $0 \%(0 / 22)$ & $0-15.44 \%^{\mathrm{b}}$ & $\begin{array}{l}1.87 \%(2 / \\
107)\end{array}$ & $0.23-6.59 \%$ \\
\hline $\begin{array}{l}\text { Undifferentiated histologic type, LVI negative, ulcer } \\
\text { negative, size } \leq 2 \mathrm{~cm}\end{array}$ & $\begin{array}{l}1.17 \%(3 / \\
257)\end{array}$ & $0.24-3.37 \%$ & $\begin{array}{l}1.36 \%(2 / \\
147)\end{array}$ & $0.17-4.83 \%$ & $\begin{array}{l}0.91 \%(1 / \\
110)\end{array}$ & $0.02-4.96 \%$ \\
\hline
\end{tabular}

CI confidence interval, LVI lymphovascular invasion

a The CI was estimated on the basis of the exact binomial distribution.

b One-sided $97.5 \%$ CI

undifferentiated mucosal EGCs, even if the EGC lesions are confined to the LP and meet the expanded indication criteria for endoscopic resection. Studies with a larger number of patients and long-term follow-up will be needed to confirm the safety of endoscopic resection for those lesions.

The main advantage of this study is that a large number of patients with mucosal EGC were included in the analyses. Therefore, it was possible to evaluate the risk of lymph node metastasis among mucosal EGC patients, and also according to the depth of tumor invasion within the mucosal layer.

This study also had several limitations. First, it was retrospective study, and only patients who underwent surgery were included. Thus, possible selection bias was unavoidable. Second, many of the patients with mucosal EGCs underwent endoscopic resection instead of surgery, especially for EGCs invading the LP. As a result, the incidence rates for lymph node metastasis and the upper limit of the CI might have been overestimated.

In conclusion, EGC lesions invading the MM had a higher rate of lymph node metastasis than those confined to the LP. There was a nonnegligible rate of lymph node metastasis in EGCs that invaded the MM, even though the lesions met the expanded indication criteria for endoscopic resection, especially the criterion of differentiated histologic type of tumors $3 \mathrm{~cm}$ or smaller with ulceration. Further study is needed to evaluate whether different treatment criteria for endoscopic resection are needed for LP-confined and MM-invading EGCs.

\section{Compliance with ethical standards}

Conflict of interest The authors declare that they have no conflict of interest.

Grant support This work was supported by grant 1310280 from the National Cancer Center, Korea.

Ethical standards All procedures followed were in accordance with the ethical standards of the Institutional Review Board of the National Cancer Center, Korea (Institutional Review Board number NCC2014-0214). Informed consent for all included patients was waived by the Institutional Review Board because of the low risk of this study.

\section{References}

1. Soetikno R, Kaltenbach T, Yeh R, Gotoda T. Endoscopic mucosal resection for early cancers of the upper gastrointestinal tract. J Clin Oncol. 2005;23:4490-8.

2. Oyama T, Tomori A, Hotta K, Morita S, Kominato K, Tanaka M, et al. Endoscopic submucosal dissection of early esophageal cancer. Clin Gastroenterol Hepatol. 2005;3:S67-70.

3. Higuchi K, Tanabe S, Koizumi W, Sasaki T, Nakatani K, Saigenji $\mathrm{K}$, et al. Expansion of the indications for endoscopic mucosal resection in patients with superficial esophageal carcinoma. Endoscopy. 2007;39:36-40.

4. Li B, Chen H, Xiang J, Zhang Y, Kong Y, Garfield DH, et al. Prevalence of lymph node metastases in superficial esophageal squamous cell carcinoma. J Thorac Cardiovasc Surg. 2013;146:1198-203.

5. Gotoda T, Yanagisawa A, Sasako M, Ono H, Nakanishi Y, Shimoda $\mathrm{T}$, et al. Incidence of lymph node metastasis from early gastric cancer: estimation with a large number of cases at two large centers. Gastric Cancer. 2000;3:219-25. 
6. Kwee RM, Kwee TC. Predicting lymph node status in early gastric cancer. Gastric Cancer. 2008;11:134-48.

7. Lehnert T, Erlandson RA, Decosse JJ. Lymph and blood capillaries of the human gastric mucosa. A morphologic basis for metastasis in early gastric carcinoma. Gastroenterology. 1985;89:939-50.

8. Listrom MB, Fenoglio-Preiser CM. Lymphatic distribution of the stomach in normal, inflammatory, hyperplastic, and neoplastic tissue. Gastroenterology. 1987;93:506-14.

9. Goseki N, Koike M, Yoshida M. Histopathologic characteristics of early stage esophageal carcinoma. A comparative study with gastric carcinoma. Cancer. 1992;69:1088-93.

10. Hölscher AH, Drebber U, Mönig SP, Schulte C, Vallböhmer D, Bollschweiler E. Early gastric cancer: lymph node metastasis starts with deep mucosal infiltration. Ann Surg. 2009;250:791-7.

11. Japanese Gastric Cancer Association. Japanese gastric cancer treatment guidelines 2010 (ver. 3). Gastric Cancer. 2011;14:113-23.

12. Lee JY, Choi IJ, Cho SJ, Kim CG, Kook MC, Lee JH, et al. Routine follow-up biopsies after complete endoscopic resection for early gastric cancer may be unnecessary. J Gastric Cancer. 2012;12:88-98.

13. Japanese Gastric Cancer Association. Japanese classification of gastric cancer: 3rd English edition. Gastric Cancer. 2011;14:101-12.

14. Hamilton SR, Lauri L. World Health Organization Classification of Tumours. Pathology and genetics. Tumours of the digestive system. Lyon. IARC; 2000.

15. Watanabe T, Itabashi M, Shimada Y, Tanaka S, Ito Y, Ajioka Y, et al. Japanese Society for Cancer of the Colon and Rectum (JSCCR) guidelines 2010 for the treatment of colorectal cancer. Int J Clin Oncol. 2012;17:1-29.

16. Kaiserling E, Krober S, Geleff S. Lymphatic vessels in the colonic mucosa in ulcerative colitis. Lymphology. 2003;36:52-61.

17. Smith KJ, Jones PF, Burke DA, Treanor D, Finan PJ, Quirke P. Lymphatic vessel distribution in the mucosa and submucosa and potential implications for T1 colorectal tumors. Dis Colon Rectum. 2011;54:35-40.
18. Akashi Y, Noguchi T, Nagai K, Kawahara K, Shimada T. Cytoarchitecture of the lamina muscularis mucosae and distribution of the lymphatic vessels in the human stomach. Med Mol Morphol. 2011;44:39-45.

19. Kang HJ, Kim DH, Jeon TY, Lee SH, Shin N, Chae SH, et al. Lymph node metastasis from intestinal-type early gastric cancer: experience in a single institution and reassessment of the extended criteria for endoscopic submucosal dissection. Gastrointest Endosc. 2010;72:508-15.

20. Chung JW, Jung HY, Choi KD, Song HJ, Lee GH, Jang SJ, et al. Extended indication of endoscopic resection for mucosal early gastric cancer: analysis of a single center experience. J Gastroenterol Hepatol. 2011;26:884-7.

21. Hanaoka N, Tanabe S, Mikami T, Okayasu I, Saigenji K. Mixedhistologic-type submucosal invasive gastric cancer as a risk factor for lymph node metastasis: feasibility of endoscopic submucosal dissection. Endoscopy. 2009;41:427-32.

22. Takizawa $\mathrm{K}$, Ono $\mathrm{H}$, Kakushima $\mathrm{N}$, Tanaka M, Hasuike $\mathrm{N}$, Matsubayashi $\mathrm{H}$, et al. Risk of lymph node metastases from intramucosal gastric cancer in relation to histological types: how to manage the mixed histological type for endoscopic submucosal dissection. Gastric Cancer. 2013;16:531-6.

23. Hirasawa T, Gotoda T, Miyata S, Kato Y, Shimoda T, Taniguchi $\mathrm{H}$, et al. Incidence of lymph node metastasis and the feasibility of endoscopic resection for undifferentiated-type early gastric cancer. Gastric Cancer. 2009;12:148-52.

24. Kim YY, Jeon SW, Kim J, Park JC, Cho KB, Park KS, et al. Endoscopic submucosal dissection for early gastric cancer with undifferentiated histology: could we extend the criteria beyond? Surg Endosc. 2013;27:4656-62.

25. Okada K, Fujisaki J, Yoshida T, Ishikawa H, Suganuma T, Kasuga A, et al. Long-term outcomes of endoscopic submucosal dissection for undifferentiated-type early gastric cancer. Endoscopy. 2012;44:122-7.

26. Abe S, Oda I, Suzuki H, Nonaka S, Yoshinaga S, Odagaki T, et al. Short- and long-term outcomes of endoscopic submucosal dissection for undifferentiated early gastric cancer. Endoscopy. 2013;45:703-7. 